\title{
Língua, leitura e linguagem no Grande Sertão: Veredas
}

LANGUAGE, READING AND SPEECH IN GRANDE SERTÃO: VEREDAS

Ana Maria Gonçalves Lysandro de ALBERNAZ *

Resumo: A tarefa de reconquista da poesia da língua, engendrada por Guimarães Rosa, não é uma mera questão de engenhosidade, embora de modo óbvio a contemple, trata-se de considerar a realidade da linguagem, explicitada na língua, como uma medida poética, desvinculando-a tanto da instrumentalidade quanto da representatividade. A iniciativa é de reatar a fenda que se abriu - a partir justamente destes dois expedientes - entre língua e linguagem conduzindo-as à sua comum originariedade. A re-instauração da força da linguagem na materialidade da língua constitui-se segundo Rosa, no modo mais completo de reaver nossa dignidade. $\mathrm{O}$ comprometimento amoroso anima a língua rosiana. Nosso artigo aborda sua relação com a linguagem a partir de uma leitura minuciosa de trechos do Grande Sertão: Veredas.

Palavras-chave: Poética; Logos; Linguagem.

Abstract: The task of recovering the poetry of language, by Guimarães Rosa, is not merely a matter of ingenuity, though it obviously involves it. The reality of the speech, as expressed in the language, must be considered as a reference to poetry, detaching it both from instrumentality and from representation. His initiative is to bridge the gap which sprang open between these two aspects: language and speech, leading them to their common origin. According to Rosa, the re-empowerment of speech in the material language is the most complete way to recover our dignity. It is the amorous commitment that animates Rosa's

* Prof. ${ }^{a}$ Dr. ${ }^{a}$ em Ciência da Literatura (Poética) pela Faculdade de Letras da Universidade Federal do Rio de Janeiro. Professora visitante Curso de PósGraduação em Língua Portuguesa e Literatura Brasileira da Universidade Severino Sombra - Vassouras-RJ. Contato: cardoso1898@oi.com.br. 
language. The article discusses its relationship with speech based on a detailed reading of extracts from his book "Grande Sertão: Veredas".

Key-words: Poetics; Logos; Speech.

O que eu vi, sempre, é que toda ação principia mesmo épor uma palavra pensada. Palavra pegante, dada ou guardada, que vai rompendo rumo.

Guimarães Rosa tem uma definição original na distinção de seu relacionamento com a língua portuguesa. Diz que ela é o aparelho de controle na articulação da ficção poética com a realidade vigente em sua obra (ROSA, 1994a, p. 35). ${ }^{1}$ Não a língua no seu estatuto padronizado, mas conforme ele mesmo a concebe, na vertência do movimento criativo de transformação na tensão com outras línguas, contemporâneas e antigas, na aproximação com a originariedade dos vocábulos e suas significações, na atenção à multiplicidade de sons, cores e possibilidades de sentido contidas em todas as palavras.

O diálogo com outras línguas provém da intuição da magnitude de enriquecimento que demanda e sustenta sua própria língua ou, o que é o mesmo, da magnitude de seu próprio enriquecimento que ele mesmo procura. Cada língua traz em si uma verdade que não pode ser traduzida (DGL, p. 51). Iniciar-se no intraduzível de outras línguas é perspectiva de avanço no inaudito da sua própria. "Aprendi algumas línguas estrangeiras apenas para enriquecer a minha própria e porque há demasiado coisas intraduzíveis, pensadas em sonhos, intuitivas, cujo verdadeiro significado só pode ser encontrado no som original" (DGL, p. 51).

Portanto, quando Rosa denomina a língua como aparelho de controle refere-se ao domínio exigido para que a verdade e o sentido da vida possam aparecer e se estabelecer, na evidência de sua posição

${ }^{1}$ ROSA, J. G. Diálogo com Günther Lorenz. In: Ficção Completa. Rio de Janeiro: Nova Aguilar, 1994. v. 1. Em razão das muitas citações deste texto no artigo, doravante, sempre que mencionado, serão usadas como referência as iniciais DGL. 
amorosa com relação ao homem e ao mundo, na compreensão de sua potencialidade poética no horizonte alargado da experiência. $\mathrm{O}$ humano da linguagem é poético, assim como cada palavra, segundo sua essência, é um poema (DGL, p. 53).

Não se trata de poetizar a realidade, mas de trazê-la à sua verdade. Desde sua vivacidade, a língua, enquanto aparelho de controle, dá a medida do vigor da linguagem e dimensiona também a dignidade do homem (DGL, p. 52). Dignidade aqui quer dizer: condução ao próprio, ou seja, homem e língua dignos entre si, fundados em um mesmo princípio de nobreza e em atestamento recíproco.

Ao pesquisar estudos linguísticos sobre a obra de Rosa, encontramos muitos trabalhos que se dedicam à coleta, classificação e esclarecimento dos vocábulos utilizados. É espantoso seu exercício criativo com a língua, e plenamente reconhecida e justificada a declaração de que a língua é sua amante e que copula e reproduz com ela (DGL, p. 47).

Neste sentido, Ronaldes de Melo e Souza (1978) observa que essa potência criadora de Rosa ultrapassa em muito aquilo que poderia se denominar um exercício de intensidade linguística na literatura. A língua rosiana, que segundo Lorenz, alguns tradutores, com orgulho, dizem dominar, ${ }^{2}$ não representa nem um fenômeno linguístico nem um fenômeno estético; mas nasce conjuntamente com um homem e um mundo renovados e surge dentro de um projeto restaurador de humanidade; e não apenas como parte desse projeto, porém enquanto seu mais radical autenticador - pois pela língua e pela linguagem o homem se reconduz a originariedade. Sendo certo que em Guimarães Rosa não há degrau metafísico entre ambas, não há um dizer "além" que o dito já imediatamente não diga, o que chega à fala, já é clímax do falar, na sua máxima potencialidade. E isso é tão significativo porque habitualmente apenas utilizamos a fala na sua voltagem mínima, só

${ }^{2}$ Diz Lorenz: "Há em seu país um professor que afirmou ter sua linguagem chegado a tal ponto, que a futura história da literatura terá de citá-la como literatura de um único homem. Fizeram-se numerosas brincadeiras sobre isso. Uma delas: um tradutor, para se recomendar a um editor, declara dominar certa quantidade de línguas vivas e mortas, inclusive a de Guimarães Rosa." (DGL, p. 44) 
como instrumento de referência ou expressão; e a partir dessa decadência, ou desistência de ser, todo modo de manifestação vai se reduzindo.

Vilém Flusser (2002) compara essa purificação efetuada na língua a partir de um processo onde todo material padronizado da linguagem é submetido a uma prensagem depurativa, ao ritual tibetano para obtenção do chamado "iapa".

Há centenas de anos os moinhos de reza do Oriente moem o trigo sagrado da língua para reduzi-lo a pó, ao pó mágico do 'iapa'. Trituram os moinhos de reza a casca dura do conceito e liberam a palavra de sua prisão lógica, para que a farinha mágica da língua se possa derramar, em torrente vivificante, sobre o espírito e sobre a alma e possa arrastá-los rumo ao silêncio do nirvana. A casca dura do conceito e a palha seca da gramática prendem e oprimem o pensamento. $\mathrm{O}$ moinho de reza, ao aniquilar o conceito e a gramática, permite ao pensamento alcançar nas asas da língua os céus do nada. Purificada das crostas do significado lógico, a língua desfralda as suas asas mágico-musicais, desfralda o 'iapa'. (FLUSSER, 2002, p. 155)

Fundamental é a conexão da língua ao "Nonada", aquilo para o qual ainda não existe palavra, e é todo porvir, ponto de partida do Grande Sertão: Veredas. Por isso para entrada na obra é essencial atravessar essa palavra, evocação ao silêncio originário, mais que seu começo, princípio de travessia atentando ao paradoxo, tão próprio ao homem, que pede silêncio, pedindo a palavra. Contudo, conforme alerta Flusser, buscando inspirar-se na sabedoria rosiana da linguagem, nós intelectuais, desde o nosso saber universitário, temos que tomar cuidado em não acumular a língua com especulações filosóficas e assim oprimir sua vertência poética.

No Grande Sertão: Veredas (ROSA, 1994b) ${ }^{3}$ encontramos o melhor exemplo do movimento oscilante da linguagem na figura do personagem Zé Bebelo. Tanto no movimento ascendente observado

${ }^{3}$ ROSA, J. G. Grande Sertão: Veredas. In: Ficção Completa. Rio de Janeiro: Nova Aguilar, 1994. v. 2. Devido ao grande número de citações, doravante, para referenciar a obra serão usadas as iniciais GSV. 
quando do julgamento comandado por Joca Ramiro, capaz de promover sua libertação ao revelar sua potência como realização que se oferece na língua, quanto no movimento descendente quando tornado chefe acaba por se abater aos efeitos de seu próprio discurso, se destituindo de poder até a perda da chefia para Riobaldo, luta que também se dá na própria língua. Não é um exercício retórico que se mostra poderoso e depois se exaure - é que a natureza de Zé Bebelo tem a peculiaridade de divulgar tanto o modo como se consuma, quanto como se consome pela força da língua.

Isso não seria próprio a todo homem? Pode ser que sim, mas desde a proeminência da conexão que se dá entre língua e linguagem, e sendo absoluta para Zé Bebelo a tentação da língua, de tanto acreditar que a domina totalmente através da eloquência e da racionalidade, finda por exibir também por inteiro o modo como é seu refém.

O julgamento na Fazenda Sempre-Verde é um dos pontos altos do Grande Sertão. Naquele lugar vicejante se realiza toda uma dramaturgia de poder a partir do desempenho da linguagem, que estabelece tensõeschave dentro da narrativa. Na realização destas possibilidades a linguagem materializada e encenada na língua atravessa a perspectiva lógico-racional, que a concebe como plano de ideias e palavras que as representam, expondo o jogo de aparência e revelação da verdade do homem. Assim, nos diálogos entre Zé Bebelo e Joca Ramiro que se dá por palavras, gestos e silêncio, se observa um duelo onde o primeiro convence não pela lábia argumentativa, que efetivamente exercita, mas porque na linguagem é firmado quem é sem impostura. E o que até então não se mostrara, que Zé Bebelo era um homem do sertão, a fala faz por aparecer.

“... o que se vê não é o que o se vê, [...]: é o que o se vai ver..." [...] “...é o mundo à revelia...” (GSV, p. 356). Assim desfecha o diálogo que origina o julgamento; o outro, que o principia, finaliza desmontando com ironia a acusação de Joca Ramiro de que não é do Sertão, não é da terra: "- "Sou do fogo? Sou do ar? Da terra é a minhoca - que galinha come e cata: esgaravata!” (GSV, p. 364). Nesses diálogos, onde antecipa a decisão do julgamento, embora não possa definir seu destino que será indicado por Joca Ramiro, percebemos como Zé Bebelo se revela a partir do que nele se fala, mostrando não apenas quem é e quem não é, mas quem pode ser, assim ascende e alcança a medida do 
seu interlocutor, Joca Ramiro, que o reconhece e respeita, simpaticamente.

Extraordinário desde a ordinariedade, Zé Bebelo é do Sertão onde têm lugar não as dicotomias, mas a alta voltagem das tensões que surpreendem nas contrapartidas e vinculações impensadas.

Zé Bebelo não era réu no real! Ah, mas, no centro do sertão, o que é doideira às vezes pode ser a razão mais certa e de mais juízo! Daquela hora em diante, eu cri em Joca Ramiro. Por causa de Zé Bebelo. Porque, Zé Bebelo, na hora, naquela ocasião, estava sendo maior do que pessoa. (GSV, p. 400)

Por outro lado, transparecendo sua humanidade Zé Bebelo se deixa decair exatamente pela fala da linguagem. Depois de derrotados na batalha na Fazenda dos Tucanos, posta em dúvida sua fidelidade aos jagunços por Riobaldo, obrigados a fugir a pé no meio da noite; paralisado pelo temor, desnorteado - "Sempre Zé Bebelo não desistia de palavrear, a raleza de projetos, como faz-de-conta. A mó de moinho, que, nela não caindo o que moer, mói assim mesmo, si mesma, mói, mói” (GSV, p. 577). Desde a mesma prisão lógica das palavras, a mó do moinho verte o "iapa” ou, como a mó de Zé Bebelo, mói ensimesmada, se fecha, voltada para dentro, investida de uma glória impossível. Numa conversa dele com o fazendeiro Seo Habão, primeiro Riobaldo repara como "aos poucos mais proseava, com ensejos de ir mostrando a valia declarada que tinha, de jagunço chefe famoso; e daí, sutil, se reconhecia da parte dele um certo desejo de agradar ao outro." (GSV, p. 588). Em seguida, nesse movimento de declínio, intensifica o fraquejo e não podendo mais nutrir sua fala de si mesmo, se dedica a agarrar o discurso do fazendeiro, já perdido de quem era.

Daí, assim ia sendo que, mesmo sem sentir, o próprio Zé Bebelo se via principiando a ter de falar com ele em todas as pestes de gado, e nas boas leiras de vazante, no feijão da seca e nos arrozais cacheando, em que os passarinhos de Deus viram em a má praga. Com efeito, nos intervalos daquela dividida conversa, não sei o que Zé Bebelo sentia nem achava. (GSV, p. 589) 
Até que finalmente sucumbe: Riobaldo, que inicia por troça e diversão remedando seu estilo grandioso, acaba lhe usurpando a chefia. Nesse episódio de trânsito e reconhecimento de poder, Zé Bebelo desvenda na fala sua identidade contestada, demonstrando na própria incapacidade de responder à pergunta “... quem é que é o Chefe? ...” (GSV, p. 621) que já não o era - mesmo ainda o sendo.

- 'A rente, Riobaldo! Tu o chefe, chefe, é: tu o Chefe fica sendo... Ao que vale!...' - ele dissezinho fortemente, mesmo mudado em festivo, gloriando um fervor. Mas eu temi que ele chorasse. Antes, em rosto de homem e de jagunço, eu nunca tinha avistado tantas tristezas. (GSV, p. 624)

O que esperamos demonstrar, a partir da leitura das falas de Zé Bebelo é como a poesia, e em particular na prosa poética do Grande Sertão: Veredas, a fala de um personagem implica mais que uma maneira de expressão, e também mais que uma visão de mundo ou o reflexo de uma recôndita intimidade. Ao deixar que a própria linguagem fale Zé Bebelo e todos os outros personagens, os faz participar de uma poética, e isso reforça o que lhes é próprio - torna-os "personagentes". 4 Não consistindo em instrumento de comunicação e renunciando à tentativa de refletir subjetividade, a potência da linguagem trazida à língua, descobridora do homem que a fala, significa constituição a partir da vertência da vida e, assim, encontro do próprio e apreço pela singularidade de quem fala. Quando o poeta deixa que a linguagem ressoe na fala dos personagens, abandonando-os à apropriação da linguagem, na verdade só permite que repercuta neles o que dispõe para si mesmo no ato de criar. O habitante do Sertão rosiano é o homem reconduzido à poesia que lhe é constitutiva, assim como as

${ }^{4}$ No conto "Darandina”, das Primeiras Estórias (1969, p. 135-149), Guimarães Rosa encontra nessa denominação o possível descoberto que se liberta, a partir da luta com as definições que fixam os personagens constituídos, tornandoos programáveis e previsíveis. Aliás, não só neste conto, mas em todas as Primeiras Estórias, e em toda a obra de Rosa é observado o abismo entre um e outro estatuto, e a possibilidade do "salto mortale", a percepção da transposição. 
palavras de sua língua são as palavras do dicionário elevadas à dignidade da linguagem - no que se nomeia logos, poesia e pensamento. Não se trata de uma perspectiva do homem, ou da perspectiva de um homem, mas condução amorosa ao próprio. $O$ humano é poético, a linguagem é poética, e cada palavra é um poema (DGL, p. 53). Portanto, não se poetiza a realidade; a realidade é poética.

Desse modo, Guimarães Rosa segue o princípio referido no princípio deste artigo que reconhece no seu relacionamento com a língua o aparelho de controle que articula em sua obra poesia e realidade. Este "relacionamento" e o que se gera do que designa, "o aspecto metafísico da língua que faz com que [sua] linguagem antes de tudo seja [sua]" (DGL, p. 53), compreendemos como o que se denomina interpretação - hermenêutica - leitura apropriante e diálogo com a vida, experiência humana de mundo.

A referência primordial na sua relação com a língua, seu “elemento metafísico" (DGL, p. 45), corresponde ao encantamento com a originariedade, isto é, ao brotar das coisas, modo como aparecem se ocultando, a própria physis que só se pronuncia na língua como palavra desde o ver inaugural. Este é o procedimento de Rosa que "implica na utilização de cada palavra como se ela tivesse acabado de nascer, para limpá-la das impurezas da linguagem cotidiana e reduzi-la ao seu sentido original" (DGL, p. 46), libertando-a para a vida que a partir dela se revela. Escutar esse sentido, cuidar para que se resguarde e se preserve íntegro na palavra é então um princípio de preservação do próprio viver - a começar pelo seu mesmo.

A partir daí, surge a concepção de uma autobiografia como dicionário (DGL, p. 46). Rosa o percebe não como um acúmulo de conteúdos, mas enquanto um princípio, uma abertura que é a propriedade de nomear. Nessa abertura a possibilidade de aproximação compreensiva das coisas se presentifica, se estabelece um diálogo, um caminho de linguagem, a mútua requisição de homem e mundo.

Geralmente entendemos como autobiografia a descrição feita por um autor das referências que elege mais significativas da sua vida; nada a ver com um impessoal dicionário. Mas na biografia pessoal conta-se a personalidade que para Rosa deve ser mantida encarcerada na experiência da criação (DGL, p. 53). Na configuração da personalidade o que está em jogo é a individualidade que nos encerra em nós mesmos; portanto, o encarceramento da personalidade na 
experiência da criação, proposto por Rosa, não é mais do que aprisionar o que aprisiona e é em si mesmo prisioneiro. Onde houver pessoalidade em ação, não há poesia.

Entre dicionário e autobiografia vigora a tensão de singularidade e totalidade, identidade e diferença, onde o infinito é mediador na impossibilidade de determinar quaisquer umas dessas instâncias (Como determinar onde é o fim do uno e o princípio do único?). Uma biografia que não se extraviasse em dados pessoais proviria desta tensão, porque nela está a existência do homem que somos no cada um que poderíamos ser, na nossa incompartilhável solidão. Quando Rosa diz que "no sertão o homem é o eu que ainda não encontrou o tu" (DGL, p. 50), fala dessa tensão que permanece como tensão mesmo, isto é, não é a etapa intermediária de uma situação final onde afinal se separam eu e tu. É porque não há a separação que o diferenciado aparece. A linguagem que reúne e revela como um só é a possibilidade de manifestação de todas as singularidades. A língua rosiana, como via de aparecimento da linguagem, oferece o ressurgimento da própria língua brasileira, como "língua do homem de amanhã, depois de sua purificação” (DGL, p. 50), ou seja, língua do homem do sertão em travessia.

Na leitura do Grande Sertão: Veredas descobrimos o que é a língua pensando, o que é a língua sendo poesia, o que é a língua criando, frutificando, florescendo, enquanto "meditação ou aventura. Às vezes, juntas, as duas coisas: aventura e meditação” (ROSA, 2003, p. 239), como afirma ao seu tradutor alemão, Curt Meyer-Clason. Poeticamente, ambas as veredas se equivalem.

$\mathrm{Na}$ experiência da língua-linguagem estamos sempre em via de recriação, isto é, redescoberta de nossa identidade. Um exemplo comentado com Meyer-Clason é um trecho em que Riobaldo, como o chefe Urutu-Branco, está com as prostitutas do Verde-Alecrim, e uma delas, referindo-se à possibilidade de convidar o jagunço Felisberto que está na porta como vigia para sua companhia, diante da negativa de Riobaldo, lhe pergunta: “Tu não repartindo, tu tem?” (GSV, p. 757). Guimarães Rosa orienta, então, o tradutor alemão acerca do sentido que procurara com essa frase: "a gente só possui, realmente, uma coisa, quando a repartindo com outros. Só se tem, de fato, o que se reparte.” E ainda acrescenta: "(Ousado, mas, religiosamente, certo.)" (ROSA, 2003, p. 259). 
Nessa frase, a fala rosiana é saturada de religiosidade, como ele afirmou, no entanto não é, simplesmente, a visão religiosa do escritor Guimarães Rosa que está colocada. Talvez só uma meretriz, uma mulher tão dadivosa como essa Maria-da-Luz, herdeira das antigas prostitutas sagradas, harmoniosa doadora da fertilidade e do prazer, esteja honestamente à altura do que diz essa frase. Nas suas palavras e no modo da sua interrogação a frase projeta um fundamento existencial totalmente abstraído de qualquer sentido dogmático.

Finalmente, mais um exemplo também fornecido a MeyerClason, nesse aclarar da língua rosiana; encontra-se nas palavras de Riobaldo na cena do Pacto com o Diabo, nas Veredas Mortas, que diz: "Ah, acho que não queria mesmo nada, de tanto que eu queria só tudo. Uma coisa, a coisa, esta coisa: eu somente queria era - ficar sendo!" (GSV, p. 559 - grifo do autor).

O esclarecimento concedido por Rosa se refere ao trecho em negrito: "É uma solução metafísica. Cada um de nós ainda não é o que "é", tem de esforçar-se por chegar a ser." (2003, p. 288). Nesse sentido tão denso pretendido na frase final se concentra não apenas o pacto, mas toda a travessia, a própria narrativa. Para acompanhar a ressonância do que é no como se diz, alcançar manifestando o que é, tarefa aparentemente tão simples, e que, no entanto, se verifica tão árdua, Guimarães Rosa realiza um bailado de palavras e sintaxe e pontuação que aponta, mas não esgota o sentido buscado. Sua esperança na língua se fundamenta no pertencimento à linguagem, na confiança de que a partir do "ficar sendo", chegar a dizer é chegar a ser.

\section{Referências}

FLUSSER, V. O 'Iapa' de João Guimarães Rosa. In: Da religiosidade: a literatura e o senso de realidade. São Paulo: Escrituras, 2002. p. $155-160$.

ROSA, J. G. Darandina. In: Primeiras Estórias. Rio de Janeiro: José Olympio, 1969. p. 135-149. 
. Diálogo com Günther Lorenz. In: . Ficção Completa

em 2 volumes. Rio de Janeiro: Nova Aguilar, 1994a. v. 1.

Grande Sertão: Veredas. Rio de Janeiro: Nova Aguilar, 1994b. v. 2 .

. Correspondência com seu tradutor alemão Curt MeyerClason: (1958-1967). Rio de Janeiro: Nova Fronteira/Academia Brasileira de Letras; Belo Horizonte: Editora da UFMG, 2003.

SOUZA, R. M. Ficção e verdade. Diálogo e catarse em 'GS:V'. Brasília: Clube de Poesia, 1978. 